\title{
Clinical practice guidelines for the use of colony-stimulating factors in cancer treatment: Implications for oncology nurses
}

\author{
Nora Kearney $^{\mathrm{a}, *}$, Christopher Friese ${ }^{\mathrm{b}}$
}

${ }^{a}$ Cancer Care Research Centre, University of Stirling, Unit 1, Scion House, Stirling FK9 4NF, Scotland

bDana-Farber Cancer Institute, 44 Binney Street, Boston, MA 02115, USA

\section{KEYWORDS}

Chemotherapy-induced neutropenia; Febrile neutropenia; Prophylaxis; Colony-stimulating factors; Granulocyte colonystimulating factors; Clinical guidelines

\begin{abstract}
Summary
Chemotherapy-induced neutropenia $(\mathrm{CIN})$ is a common and serious toxicity of cancer chemotherapy. It can lead to febrile neutropenia (FN), which often requires patients to be hospitalised for intravenous antibiotic therapy. Chemotherapy dose reductions or delays, which can compromise clinical outcomes, may also result from CIN and FN. Prophylactic use of colony-stimulating factors (CSFs) reduces the incidence, duration, and severity of $\mathrm{FN}$, and there is evidence that it helps maintain scheduled chemotherapy dose delivery. In 2006, three organisations published new or updated guidelines for the use of CSFs in cancer treatment. Each recommends that FN risk be determined individually for each patient, taking into account patient- and disease-specific risk factors, the chemotherapy regimen, and treatment intent. Particular consideration should be given to patients who are $\geqslant 65$ years old, receiving chemotherapy regimens associated with $\geqslant 20 \%$ risk of $\mathrm{FN}$, receiving dose-dense chemotherapy, and receiving treatment that is adjuvant, potentially curative, or intended to prolong survival. Accordingly, oncology nurses can play an important role in assessing and identifying patients at risk for FN before every chemotherapy cycle. There is evidence that, regardless of practice type or size, implementing guidelines for CSF use within a multidisciplinary team improves patient outcomes.
\end{abstract}

(c) 2007 Elsevier Ltd. All rights reserved.

\section{Zusammenfassung}

Die Chemotherapie-induzierten Neutropenie (CIN) stellt eine häufige und ernste unerwünschte Wirkung einer Chemotherapie dar. Eine CIN kann eine febrile Neutropenie zur Folge haben (FN), bei der oft eine intravenöse Antibiotikatherapie unter stationären Bedingungen indiziert ist. Ferner kann es bei einer CIN oder FN erforderlich sein, die Dosierung der Chemotherapeutika zu reduzieren oder die Chemotherapie zu verzögern. Durch prophylaktische Anwendung von koloniestimulierenden Faktoren (CSF) lassen sich Inzidenz, Dauer und Schwere einer FN verringern, und es existieren Hinweise, dass prophylaktisch applizierte CSF die Einhaltung des Chemotherapie-Zeitplans erleichtern. Im Jahr 2006 veröffentlichten drei Institutionen neue bzw. aktualisierte Richtlinien für die Anwendung von CSF im Rahmen einer Krebstherapie. Diese drei Institutionen empfehlen, das individuelle FN-Risiko des jeweiligen Patienten zu ermitteln, wobei patienten- und

\footnotetext{
*Corresponding author. Tel.: +441786460062; fax: +441786460060.

E-mail addresses: nora.kearney@stir.ac.uk (N. Kearney), christopher_friese@dfci.harvard.edu (C. Friese).
} 
krankheitsspezifische Risikofaktoren, das Chemotherapie-Regime sowie das Behandlungsziel zu berücksichtigen sind. Besondere Vorsicht ist bei Patienten ab 65 Jahren geboten, denen ein mit einem FN-Risiko $\geq 20 \%$ assoziiertes Chemotherapie-Regime oder eine Dosedense-Chemotherapie verabreicht wird, sowie bei Patienten, die eine adjuvante, potentiell kurative Behandlung oder eine Therapie erhalten, die lebensverlängernd wirken soll. Onkologischen Pflegekräften kommt daher eine wichtige Rolle bei der Evaluation und Identifizierung von Patienten mit erhöhtem FN-Risiko vor Beginn eines ChemotherapieZyklus zu. Es existieren Hinweise darauf, dass die Anwendung von Richtlinien für die Anwendung von CSF innerhalb eines interdisziplinären Teams zu einer Verbesserung des Outcomes der Patienten führt, unabhängig von der Art oder der Größe der Arztpraxis. (c) 2007 Elsevier Ltd. All rights reserved.

\section{Introduction}

Chemotherapy-induced neutropenia (CIN), defined as an absolute neutrophil count below $500 / \mathrm{mm}^{3}$, is a common and serious toxicity of chemotherapy. It can lead to febrile neutropenia (FN), which may result in life-threatening infection (Crawford et al., 2004a). Patients with FN often require immediate hospitalisation - which is associated with substantial morbidity, mortality, and cost-for empiric treatment with broad-spectrum antibiotics (Caggiano et al., 2005; Kuderer et al., 2006). In addition, CIN and FN often require dose reductions or treatment delays, which can compromise long-term survival in patients with curable cancers (Lyman and Kuderer, 2003).

The prevalence of CIN makes surveillance for $\mathrm{FN}$ a routine concern of oncology nurses. Pettengell et al. (2006) recently conducted a prospective observational study of routine practice at 34 centres in western Europe that showed that grade $4 \mathrm{CIN}$ (defined in this study using the Common Toxicity Criteria as absolute neutrophil count [ANC] $<500 / \mathrm{mm}^{3}$ ) occurred in $40 \%$ (95\% confidence interval [CI], 28-53\%) of 65 patients with Hodgkin lymphoma and $54 \%(95 \% \mathrm{Cl}$, 47-60\%) of 240 patients with non-Hodgkin lymphoma (NHL). The rates of $\mathrm{FN}$ were $15 \%(95 \% \mathrm{Cl}, 8-27 \%)$ and $22 \%$ $(95 \% \mathrm{Cl}, 17-28 \%)$ in the two groups, respectively. A retrospective chart review of patients with breast cancer treated at 16 Spanish hospitals between April and June of 2005 showed that $18 \%$ of 83 patients suffered from more than one FN episode (Mayordomo et al., 2006). In the United States, a prospective registry study of more than 4000 patients treated with systemic chemotherapy for one of six major cancer types documented that $24 \%$ of patients had CIN and $14 \%$ had FN (Crawford et al., 2004b).

These findings from community practice are important, because most of the other data about the incidence of CIN and $\mathrm{FN}$ was derived from randomised, controlled trials that tend to exclude older patients and those with poor performance status. Moreover, many reports on such trials are incomplete. In a systematic review of trials in earlystage breast cancer (ESBC) and NHL published between 1990 and 2000, Dale et al. (2003) found that 35\% of articles did not report the incidence or severity of myelotoxic effects of chemotherapy. The data that were available were reported using varying measures, and results for the same or similar chemotherapy regimens varied widely. Thus, the true risk of $\mathrm{FN}$, even for commonly studied regimens, remains to be determined.
Randomised, controlled trials (Crawford et al., 1991; Trillet-Lenoir et al., 1993; Holmes et al., 2002; Green et al., 2003; Timmer-Bonte et al., 2005; Vogel et al., 2005) and meta-analyses (Lyman et al., 2002; Kuderer et al., 2005) have established that prophylactic use of granulocyte colony-stimulating factor (G-CSF) reduces the incidence, duration, and severity of FN. In 2005 and 2006, the American Society of Clinical Oncology (ASCO) (Smith et al., 2006), the European Organisation for Research and Treatment of Cancer (EORTC) (Aapro et al., 2006), and the National Comprehensive Cancer Network (NCCN) (Crawford et al., 2006) published new or updated guidelines for the prophylactic use of CSF. The main purposes of this article are to introduce oncology nurses to these three sets of guidelines, to discuss the role of nurses in the use and implementation of these guidelines, and to review their resultant contribution to improved patient outcomes. The article first reviews the adverse consequences of CIN and FN, and explains the latest findings about the clinical efficacy of prophylactic G-CSF.

\section{Why should nurses care about CIN and FN?}

It has been known for 40 years that the risk of $\mathrm{FN}$, and hence the risk of life-threatening infection, increases in direct relation to the duration and severity of neutropenia (Bodey et al., 1966). Approximately a third of patients with FN have a microbiologically confirmed infection (Gáytan-Martinez et al., 2000; Cordonnier et al., 2005). In Europe, there is a trend of significantly increased incidence of gram-negative bacteraemias in neutropenic patients and in a trial of empirical therapy for FN conducted by the EORTC International Antimicrobial Therapy Group in 2000, $12 \%$ of $341 \mathrm{FN}$ episodes were related to single-agent gram-negative bacteraemia, compared with $7.5 \%$ in a similar trial conducted in $1993(p=0.05)$ (De Bock et al., 2001). Thanks to the introduction of a wide range of effective anti-infectives and CSFs, most patients who have FN usually require only short hospitalisations and have successful outcomes (Lyman and Kuderer, 2003). However, death associated with FN is far from rare. According to a review of data on $20,780 \mathrm{CIN}$ related hospitalisations in seven US states in 1999, the inpatient mortality rate was 7\% (Caggiano et al., 2005). The rate was even higher, $10 \%$, in a retrospective review of 6 years of data in more than 41,000 patients hospitalised for FN in 115 US medical centres (Kuderer et al., 2006). 
For the 7995 patients with more than one major comorbidity, the death rate escalated to $\geqslant 21 \%$.

Another adverse clinical consequence of $\mathrm{FN}$ is the frequent need for chemotherapy dose reductions or delays. Such deviations from the schedule reduce the relative dose intensity $(\mathrm{RDI})$ - the percentage of the planned dose intensity (defined as the amount of drug delivered per unit time) that is actually delivered to the patient (see example in Figure 1). Maintaining RDI is important in increasing the likelihood of improved overall and disease-free survival (Budman et al., 1998; Kwak et al., 1990; Epelbaum et al., 1990). Suboptimal RDI has been documented to be a common problem for patients who develop FN. In the European study by Pettengell et al. (2006), about $30 \%$ of patients with lymphoma received an RDI $\leqslant 85 \%$ of what was planned, and multivariate regression analysis showed that the occurrence of FN in the first cycle was a predictor of low RDI. A retrospective chart review carried out in 16 Spanish hospitals in 2005 found that of 83 patients with breast cancer who developed $\mathrm{FN}, 42 \%$ required one or more chemotherapy dose reductions, $31 \%$ required one or more chemotherapy dose delays, and $17 \%$ discontinued chemotherapy altogether (Mayordomo et al., 2006). Another subgroup analysis of this study was in 67 patients with lymphoma who developed FN. Of these, $17 \%$ had dose reductions, 24\% had dose delays, and 15\% discontinued chemotherapy (López et al., 2006).

Studies of community practice in the United States have also shown that CIN-related and FN-related dose modifica- tions are common in patients with ESBC (Link et al., 2001; Lyman et al., 2003) and NHL (Picozzi et al., 2001; Lyman et al., 2004). These observations are of concern because the reduction of planned dose has been associated with poorer long-term disease-free survival and overall survival in potentially curable malignancies (Ardizzoni et al., 2005; Bonadonna et al., 2005; Bonneterre et al., 2005; Early Breast Cancer Trialists' Collaborative Group, 2005). Yet in the systematic review by Dale et al. (2003), 39\% of reports on ESBC trials and 54\% of reports on NHL trials lacked data about delivered RDI. Thus, because of incomplete reporting, it is not possible to determine the true impact of severe and $\mathrm{FN}$ on the delivered dose intensity associated with various chemotherapy regimens.

In addition to clinical impact, the economic impact of FN is considerable. In an early study in the United Kingdom, consultant oncologists at six hospitals completed a detailed questionnaire on how they would treat a patient admitted for FN (Leese, 1993). Based on their responses, the estimated average cost of FN was $£ 1649$ per episode in $1990 / 1991$ prices. Hospitalisation was the largest single factor, accounting for $62 \%$ of estimated cost, and an additional $19 \%$ of the cost was associated with antibiotic treatment. The predicted average length of stay, which was 6 days, was similar in all six hospitals. Subsequently, the cost of hospitalisation for a patient with a neutropenic event was estimated at $£ 2290$ in 1996 prices, equivalent to approximately $€ 2750$ in 2002 (Hackshaw et al., 2004). More recently, in 2005, the multicenter review in Spain

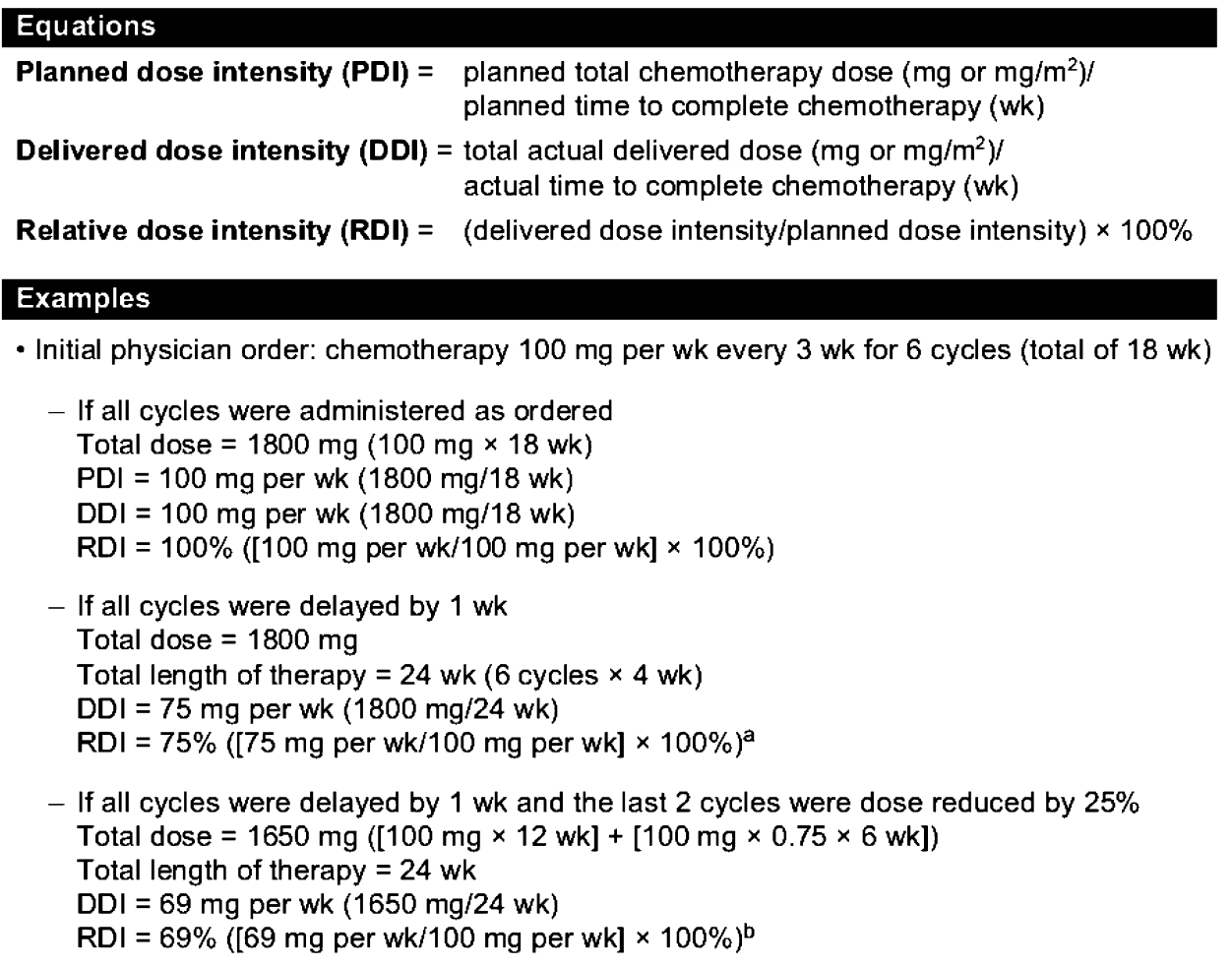

Figure 1 Calculating relative dose intensity (Lenhart, 2005). Reproduced with permission of Oncology Nursing Society, from Relative dose intensity: improving cancer treatment and outcomes, Lenhart, Oncology Nursing Forum, volume 32(4), 2005; permission conveyed through Copyright Clearance Center, Inc.: ${ }^{a}$ the patient received $75 \%$ of the chemotherapy in the dose or time frame originally ordered by the physician and ${ }^{b}$ the patient received $69 \%$ of the chemotherapy in the dose or time frame originally ordered by the physician. 
determined that the average total cost per episode was ¿4514 for patients with lymphoma (López et al., 2006) and C3519 for patients with breast cancer (Mayordomo et al., 2006). The median length of hospital stay was 8 days for patients with lymphoma and 6 days for patients with breast cancer, and, as in the early UK study, the main drivers of the cost of managing FN were hospitalisation and antibiotic treatment (López et al., 2006; Mayordomo et al., 2006).

In the United States, the 1999 review of administrative data showed that the average cost of CIN-related hospitalisation was $\$ 13,372$ per episode (Caggiano et al., 2005). The retrospective study at 115 US centres found that the average length of stay was $11.5 \pm 0.1$ days and that the average cost per FN episode was $\$ 19,110 \pm \$ 305$ (Kuderer et al., 2006). Not included in these calculations are the indirect costs of care for FN, such as the cost associated with lost or impaired ability to work, and the cost of lost productivity because of premature death. One US study estimated that the indirect cost of hospitalisation for FN was approximately $\$ 5000$ per episode, mostly due to lost wages (Cosler et al., 2004).

\section{Benefits of prophylactic G-CSF}

The use of G-CSF reduces the risk of FN and FN-related hospitalisation across a broad range of malignancies and chemotherapy regimens. A meta-analysis of the first randomised, controlled trials (five trials of filgrastim, three trials of lenograstim) showed that the prophylactic use of G-CSF significantly reduced the incidence of $\mathrm{FN}$ by $62 \%$ (odds ratio [OR], $0.38 ; 95 \% \mathrm{Cl}, 0.29-0.49 ; p=0.001$ ) and significantly reduced the risk of documented infection by $49 \%$ (OR, 0.51; 95\% Cl, 0.36-0.73, $p=0.001$ ) (Lyman et al., 2002). The registrational trials of pegfilgrastim, a G-CSF that can be administered once per chemotherapy cycle, showed a reduction in the incidence of $\mathrm{FN}$ comparable to that of filgrastim (Holmes et al., 2002; Green et al., 2003).

Part of the impetus for the new guidelines was the discovery that pegfilgrastim reduces the risk of $\mathrm{FN}$ even when used with a chemotherapy regimen less myelotoxic than those previously investigated. Vogel et al. (2005) showed that in patients with breast cancer treated with docetaxel $100 \mathrm{mg} / \mathrm{m}^{2}$ every 3 weeks (a regimen associated with $\mathrm{FN}$ rates of $10-20 \%$ in previous clinical trials), the incidence of $\mathrm{FN}$ was $1 \%$ in the G-CSF arm versus $17 \%$ in the control arm, a reduction of $94 \%(p<0.001)$. The use of anti-infectives and the number of hospitalisations were also reduced significantly $(p<0.001$ for both). These observations led to the updated recommendation that appears in all three sets of new guidelines: adults need primary prophylaxis with CSFs when the overall risk of $\mathrm{FN}$ is $\geqslant 20 \%$.

The Vogel trial was included in an updated meta-analysis that also comprised 10 trials of filgrastim and three trials of lenograstim, collectively involving 3091 patients (Kuderer et al., 2005). Besides confirming that the use of G-CSF significantly reduces the risk of $\mathrm{FN}$, the updated metaanalysis showed that the prophylactic use of G-CSF reduced the risk of infection-related mortality by $45 \%$ (OR, $0.55 ; 95 \%$ $\mathrm{Cl}, 0.36-0.84, p=0.005)$. The patients included in the 14 trials were generally younger and had fewer comorbidities than patients in routine practice, so the benefit of G-CSF prophylaxis with regard to infection-related mortality may actually be greater (Lyman, 2005). Finally, the meta-analysis showed that the use of G-CSF significantly increased the delivery of full-dose chemotherapy on schedule. The average RDI in control and G-CSF patients was $88 \%(95 \% \mathrm{Cl}$, $86-90 \%)$ and $95 \%(95 \% \mathrm{Cl}, 93-96 \%)$, respectively $(p<0.001)$. The ability to sustain dose intensity in patients with responsive and potentially curable malignancies is one of the most important benefits of prophylactic G-CSF, especially now that more intensive or dose-dense regimens are being used to prolong disease-free and overall survival.

\section{Creation of evidence-based guidelines for CSF prophylaxis}

Evidence-based medicine has been defined as the "conscientious, explicit, and judicious use of current best evidence in making decisions about the care of individual patients" (Sackett et al., 1996). In relation to nursing, evidence-based practice centres on the premise that making clinical decisions according to the best evidence, via the combination of research literature and clinical expertise, improves the quality of care and the patient's quality of life (Oncology Nursing Society, 2006).

Evidence-based guidelines about prophylactic CSF use provide a scientifically sound basis for determining which patients should receive growth factor support. The procedure used to develop the EORTC document (Figure 2) is typical of the usual process for creating national and international guidelines. The first step was to form an expert Working Party, which included representatives of various groups within the EORTC and other oncology groups. One of the authors of this article (NK) represented the European Oncology Nursing Society. The Working Party prospectively defined a number of questions to be addressed, such as "Is there evidence that patient-related factors increase the risk of FN?" and "Is there evidence that certain chemotherapy regimens increase the risk of FN?". Literature searches were then undertaken to identify relevant clinical studies. Because more than 5000 studies were identified, they were evaluated in an hierarchical fashion; if a question could be answered using a metaanalysis, no other studies were reviewed, but if not, phase III studies were reviewed, then phase II studies, and so on (Aapro et al., 2006).

For each question, the evidence levels used by American Society of Clinical Oncology (ASCO) (2005) were applied. For example, evidence obtained from a meta-analysis of multiple well-designed, controlled studies or from a high-power, randomised, controlled clinical trial was designated level I. The lowest level, level V, designated evidence obtained from case reports and clinical examples. Each recommendation issued in the guidelines was graded according to the strength of the evidence. For example, Grade A recommendations were supported by level I evidence or consistent findings from multiple studies of levels II, III, or IV. Grade B recommendations were supported by consistent findings from studies of levels II to IV. All of the EORTC recommendations discussed here were graded A or B. 
1. Selected questions considered relevant to G-CSF use in Europe.

\begin{tabular}{|c|}
\hline $\begin{array}{l}\text { 2. Conducted computerised literature } \\
\text { searches of MEDLINE, PreMEDLINE, } \\
\text { EMBASE, and The Cochrane Library to } \\
\text { identify relevant clinical studies } \\
\text { (31 December } 1994 \text { to } 16 \text { September 2005). }\end{array}$ \\
\hline $\begin{array}{l}\text { 3. Manually reviewed meeting abstracts } \\
\text { (2003 to 2005) and the reference lists of the } \\
\text { meta-analyses identified in step } 2 \\
\text { to ensure that all relevant evidence had } \\
\text { been identified. }\end{array}$ \\
\hline $\begin{array}{l}\text { 4. Systematically reviewed the data. } \\
\text { Recorded the positive and negative } \\
\text { evidence relevant to each question selected } \\
\text { in step } 1 \text {, and assigned a level of evidence. }\end{array}$ \\
\hline $\begin{array}{l}\text { 5. Reviewed the body of evidence available } \\
\text { to answer each question. } \\
\text { Formulated recommendations } \\
\text { and assigned a grade to each. }\end{array}$ \\
\hline
\end{tabular}

Figure 2 Process for developing the European Organisation for Research and Treatment of Cancer guidelines on granulocyte colony-stimulating factor (G-CSF) prophylaxis.

\section{Three sets of similar guidelines}

The ASCO guidelines for CSF use were first published in 1994 and have been updated several times, most recently in 2006 (Smith et al., 2006). The NCCN guidelines for CSF use were developed in 2005; minor revisions were made later in 2005 and in 2006 (Crawford et al., 2006). Expanding on earlier guidelines for use of CSFs in older adults with cancer (Repetto et al., 2003), in 2006 EORTC created more general guidelines that address the use of G-CSF to reduce the incidence of chemotherapy-induced FN in patients with lymphomas and solid tumours (Aapro et al., 2006). An impetus for the creation or revision of guidelines in 2005 and 2006 was the new evidence from the Vogel trial, discussed above, that the use of G-CSF substantially reduces the incidence of $\mathrm{FN}$ and $\mathrm{FN}$-related hospitalisation, even when the risk of $\mathrm{FN}$ associated with the chemotherapy regimen is 10-20\% (Vogel et al., 2005).

Although there are differences in emphasis, the similarities between the guidelines are striking. In particular, ASCO, EORTC, and NCCN concur that adults need primary prophylaxis with CSFs when the chemotherapy regimen is associated with a risk of $\mathrm{FN} \geqslant 20 \%$. Table 1 summarises and compares the recommendations of the three sets of guidelines regarding primary prophylaxis with CSFs and examples of such regimens are listed in Table 2 . It is expected that other chemotherapy regimens should also fall into this category, but because of the biases in reporting mentioned earlier, the true rate of $\mathrm{FN}$ is not known.

Other factors to be considered when determining whether adult patients need CSF are treatment-related risk factors (such as the extent of prior chemotherapy), patient-related factors (such as age and comorbidities), disease-related factors (such as the type and stage of the cancer), and treatment intent (curative, prolongation of life, or symptom control and palliation). The EORTC and NCCN guidelines recommend giving particular consideration to these other factors when the chemotherapy regimen is associated with intermediate risk of FN (10-20\%)-if overall $\mathrm{FN}$ is considered to be $\geqslant 20 \%$, primary prophylaxis with G-CSF is recommended. Table 3 lists common risk factors for FN.

\section{The oncology nurse's role in managing CIN and FN}

Nurses have already assumed a key role in addressing cancer-associated symptoms such as pain and nausea. They now have an opportunity to apply evidence-based guidelines to more effectively manage $\mathrm{CIN}$ and reduce the incidence of new or recurrent episodes of FN.

Across tumour types and chemotherapy regimens, the risk of $\mathrm{FN}$ is greatest in the first cycle of chemotherapy (Crawford et al., 2004b). This finding contradicts the historical notion that neutropenia is primarily a cumulative toxicity. Thus, prior to the first cycle of chemotherapy and every subsequent cycle, oncology nurses and nurse practitioners should assess patients to identify individuals at higher risk of FN, using means such as a review of medical histories, physical examinations, and laboratory studies. Clinicians can use this information to make data-driven changes to chemotherapy plans, rather than intuitive changes. During assessments of patient risk of FN, nurses should give particular attention to the chemotherapy regimens listed in Table 2 and the risk factors listed in Table 3. A sample algorithm for determining which patients are at high risk of FN appears in Figure 3, which combines recommendations from the EORTC and ASCO guidelines.

Other ways for nurses and nurse practitioners to practice in concordance with the new guidelines are to:

- Discuss guideline recommendations for any indications for G-CSF with the prescribing practitioner.

- Administer G-CSF at the recommended dose and schedule, where indicated, beginning in the first cycle of chemotherapy, as prescribed by the practitioner.

- Record reasons for the use of G-CSF in the patient's chart.

With each cycle of chemotherapy, oncology nurses should:

- Document outcomes and response to treatment before the next cycle of chemotherapy is administered.

- Monitor patients for complications, especially older patients, who are more likely to become myelosuppressed. 
Table 1 Comparison of three sets of guidelines for prophylactic use of CSFs.

\begin{tabular}{|c|c|c|c|}
\hline Parameter & EORTC (Aapro et al., 2006) & ASCO (Smith et al., 2006) & NCCN (Crawford et al., 2006) \\
\hline \multirow{2}{*}{$\begin{array}{l}\text { Primary } \\
\text { prophylaxis }\end{array}$} & Recommended for patients: & Recommended for patients: & Recommended for patients: \\
\hline & $\begin{array}{l}\text { - At } \geqslant 20 \% \text { overall risk of FN } \\
\text { - Receiving dose-dense or dose- } \\
\text { intense chemotherapy that has } \\
\text { survival benefits } \\
\text { - Receiving adjuvant therapy, } \\
\text { potentially curative treatment, } \\
\text { or treatment intended to } \\
\text { prolong survival, or in other } \\
\text { circumstances where } \\
\text { reductions in dose intensity or }\end{array}$ & $\begin{array}{l}\text { - Receiving a regimen with FN } \\
\text { risk in the range of } \geqslant 20 \% \\
\text { - At high risk of FN based on age, } \\
\text { medical history, or disease } \\
\text { characteristics } \\
\text { - Receiving dose-dense } \\
\text { chemotherapy (CSF required) } \\
\text { - } \geqslant 65 \text { years with diffuse } \\
\text { aggressive lymphoma treated } \\
\text { with CHOP or more aggressive }\end{array}$ & $\begin{array}{l}\text { - At high risk ( }>20 \% \text { ) of } \mathrm{FN} \text { or } \\
\text { another neutropenic event } \\
\text { compromising treatment and } \\
\text { receiving curative therapy, } \\
\text { adjuvant therapy, or treatment } \\
\text { expected to prolong survival } \\
\text { and improve QOL } \\
\text { - Receiving a regimen with } \mathrm{FN} \\
\text { risk }>20 \% \text {, regardless of other } \\
\text { factors }\end{array}$ \\
\hline
\end{tabular}

Additional recommendations regarding primary prophylaxis
- Give particular consideration to the elevated risk of FN in patients $>65$ years

- When assessing FN risk, consider patient-specific risk factors, the regimen, and treatment intent

- When using regimens associated with a $10-20 \%$ risk of $\mathrm{FN}$, give particular consideration to patientspecific risk factors
When determining whether patients are at high risk, consider individual patient risk factors and treatment intent
- Consider CSFs for patients at intermediate risk (10\%-20\%) of FN or other neutropenic event compromising treatment

- In determining the risk categorisation, consider the regimen and patient- and disease-specific risk factors (especially age $>65$ years), and factors that may compromise the ability to deliver full dose

Assess risk of FN Not addressed

Yes

Yes

prior to every

cycle of

chemotherapy

Secondary

prophylaxis

\begin{abstract}
Recommended for patients who Recommended for patients who
had a neutropenic complication in had an episode of FN or dose-

a prior cycle of chemotherapy limiting neutropenic event during

(without primary prophylaxis), if a the previous cycle of

reduced dose might compromise chemotherapy with the same dose

survival or treatment outcome and schedule planned for the current cycle
\end{abstract}

Not addressed

Abbreviations: ASCO, American Society of Clinical Oncology; CHOP, cyclophosphamide, doxorubicin, vincristine, and prednisone; CSF, colony-stimulating factor; EORTC, European Organisation for Research and Treatment of Cancer; FN, febrile neutropenia; NCCN, National Comprehensive Cancer Network; QOL, quality of life.

- Remind patients and their families about the potential for CIN and the need to monitor body temperature and symptoms.

- Provide patient education focused on reducing risk of infection during chemotherapy. The practices best supported by scientific evidence are thorough, frequent hand washing and drying; consistent and frequent oral care to prevent oral mucositis; and avoiding exposure to people with potential symptoms of respiratory infection (Zitella et al., 2006).

\section{Integrating guidelines into oncology nursing practice}

There are a number of compelling reasons for nurses to integrate the new guidelines about CSF prophylaxis into oncology practice (Maxwell and Stein, 2006). The evidencebased approach promotes the practice of healthcare providers making decisions based on the best available data, rather than opinion, habits, instinct, or local standards. Guidelines also promote uniformity of care. 
Table 2 Examples of chemotherapy regimens associated with $\geqslant 20 \%$ risk of febrile neutropenia. ${ }^{a}$

\begin{tabular}{|c|c|}
\hline Malignancy & Regimen \\
\hline Breast cancer & $\begin{array}{l}\text { AC } \rightarrow \text { docetaxel } \\
\text { Paclitaxel } \rightarrow \text { AC } \\
\text { Doxorubicin and docetaxel } \\
\text { Doxorubicin and paclitaxel } \\
\text { TAC } \\
\text { DD/DDG FEC } \\
\text { DDG doxorubicin } \rightarrow \text { paclitaxel } \rightarrow \\
\text { cyclophosphamide } \\
\text { DDG doxorubicin and } \\
\text { cyclophosphamide } \rightarrow \text { paclitaxel } \\
\text { DDG epirubicin and } \\
\text { cyclophosphamide }\end{array}$ \\
\hline $\begin{array}{l}\text { Small cell lung } \\
\text { cancer }\end{array}$ & $\begin{array}{l}\text { ACE }^{\mathrm{b}} \\
\text { Topotecan } \\
\text { Topotecan and paclitaxel } \\
\text { ICE } \\
\text { VICE } \\
\text { DDG ACE } \\
\text { DDG ICE } \\
\text { DDG CAV } \rightarrow \text { PE }\end{array}$ \\
\hline $\begin{array}{l}\text { Non-small cell lung } \\
\text { cancer }\end{array}$ & $\begin{array}{l}\text { Docetaxel and carboplatin } \\
\text { Etoposide and cisplatin }{ }^{\mathrm{b}} \\
\text { VIG }\end{array}$ \\
\hline $\begin{array}{l}\text { Non-Hodgkin } \\
\text { lymphoma }\end{array}$ & $\begin{array}{l}\text { DHAP } \\
\text { ESHAP } \\
\text { CHOP-14 }( \pm R) \\
\text { CHOP-21 }( \pm R) \\
\text { DD or DDG VAPEC-B } \\
\text { DD or DDG ACVBP }\end{array}$ \\
\hline Ovarian cancer & $\begin{array}{l}\text { Docetaxel } \\
\text { Paclitaxel }^{\mathrm{b}}\end{array}$ \\
\hline Urothelial cancer & $\begin{array}{l}\text { Paclitaxel and carboplatin } \\
\text { MVAC } \\
\text { DDG MVAC }\end{array}$ \\
\hline Germ cell tumours & $\begin{array}{l}\text { BOP } \rightarrow \text { VIP-B } \\
\text { VelP }\end{array}$ \\
\hline Other & $\begin{array}{l}\text { TIC (head and neck cancers) } \\
\text { MAID (sarcoma) } \\
\text { Paclitaxel and cisplatin (cervical } \\
\text { cancer) }\end{array}$ \\
\hline
\end{tabular}

Abbreviations: AC, doxorubicin and cyclophosphamide; ACE, doxorubicin, cyclophosphamide, and etoposide; ACVBP, doxorubicin or mitoxantrone with cyclophosphamide, vindesine, and bleomycin; BOP $\rightarrow$ VIP-B, bleomycin, cisplatin followed by cisplatin, ifosfamide, etoposide, and bleomycin; CAV, cyclophosphamide, doxorubicin, and vincristine; CHOP-14 $\pm R$, cyclophosphamide, doxorubicin, vincristine, prednisone administered every 14 days with or without rituximab; CHOP-21 $\pm R$, cyclophosphamide, doxorubicin, vincristine, prednisone administered every 21 days with or without rituximab; DD, dose dense; DDG, dose dense regimen supported by primary prophylactic G-CSF; DHAP, cisplatin, cytarabine, and dexamethasone; ESHAP, etoposide, methylprednisolone, cytar-
Table 2. foot note (continued)

abine, and cisplatin; FEC, cyclophosphamide, epirubicin, and fluorouracil; ICE, ifosfamide, carboplatin, and etoposide; MAID, mesna, doxorubicin, ifosfamide, and dacarbazine; MVAC, methotrexate, vinblastine, doxorubicin, and cisplatin; PE, cisplatin and etoposide; TAC, docetaxel, doxorubicin, and cyclophosphamide; TIC, paclitaxel, ifosfamide, and carboplatin; VAPEC-B, vincristine, doxorubicin, prednisolone, etoposide, cyclophosphamide, and bleomycin; VelP, vinblastine, ifosfamide, and cisplatin; VICE, vincristine, ifosfamide, carboplatin, and etoposide; VIG, vinorelbine, ifosfamide, and gemcitabine.

${ }^{a}$ Adapted from Aapro et al. (2006). Note: Results may vary for similar regimens depending on the patient population studied.

${ }^{\text {b} P a t i e n t s ~ i n ~ t h e ~ s u p p o r t i n g ~ s t u d i e s ~ h a d ~ a d v e r s e ~ r i s k ~ f a c t o r s ~}$ and may have been at increased risk of febrile neutropenia.

Table 3 Examples of risk factors for febrile neutropenia. ${ }^{a}$

Category Risk factor

Treatment- Previous history of severe neutropenia with related similar chemotherapy

Type of chemotherapy

Planned relative dose intensity $>80 \%$

Preexisting neutropenia (ANC $<1000 \mathrm{~mm}^{3}$ )

or lymphocytopaenia

Extensive prior chemotherapy

Concurrent or prior radiation therapy to marrow-containing bone

Patient- $\quad$ Age $>65$ years

related Female sex

Poor performance status (ECOG $\geqslant 2$ )

Poor nutritional status (e.g., low albumin)

Decreased immune function

Comorbidities (COPD, CVD, liver disease,

$\mathrm{DM}$, low baseline haemoglobin)

Laboratory data (hyperglycemia, elevated alkaline phosphatase, elevated bilirubin $)^{\text {b }}$

Disease- Bone marrow involvement with tumour

related Advanced or uncontrolled cancer

Elevated lactate dehydrogenase

(lymphoma)

Leukaemia

Lymphoma

Lung cancer

Abbreviations: ANC, absolute neutrophil count; COPD, chronic obstructive pulmonary disease; CVD, cardiovascular disease; DM, diabetes mellitus; ECOG, Eastern Cooperative Oncology Group scale.

${ }^{a}$ Adapted from Crawford et al. (2006).

byman et al. (2006).

Patients find this reassuring, particularly those who are seen by many different clinicians within a large healthcare system. In addition, guidelines give less-experienced healthcare providers a basis for making decisions and can help 


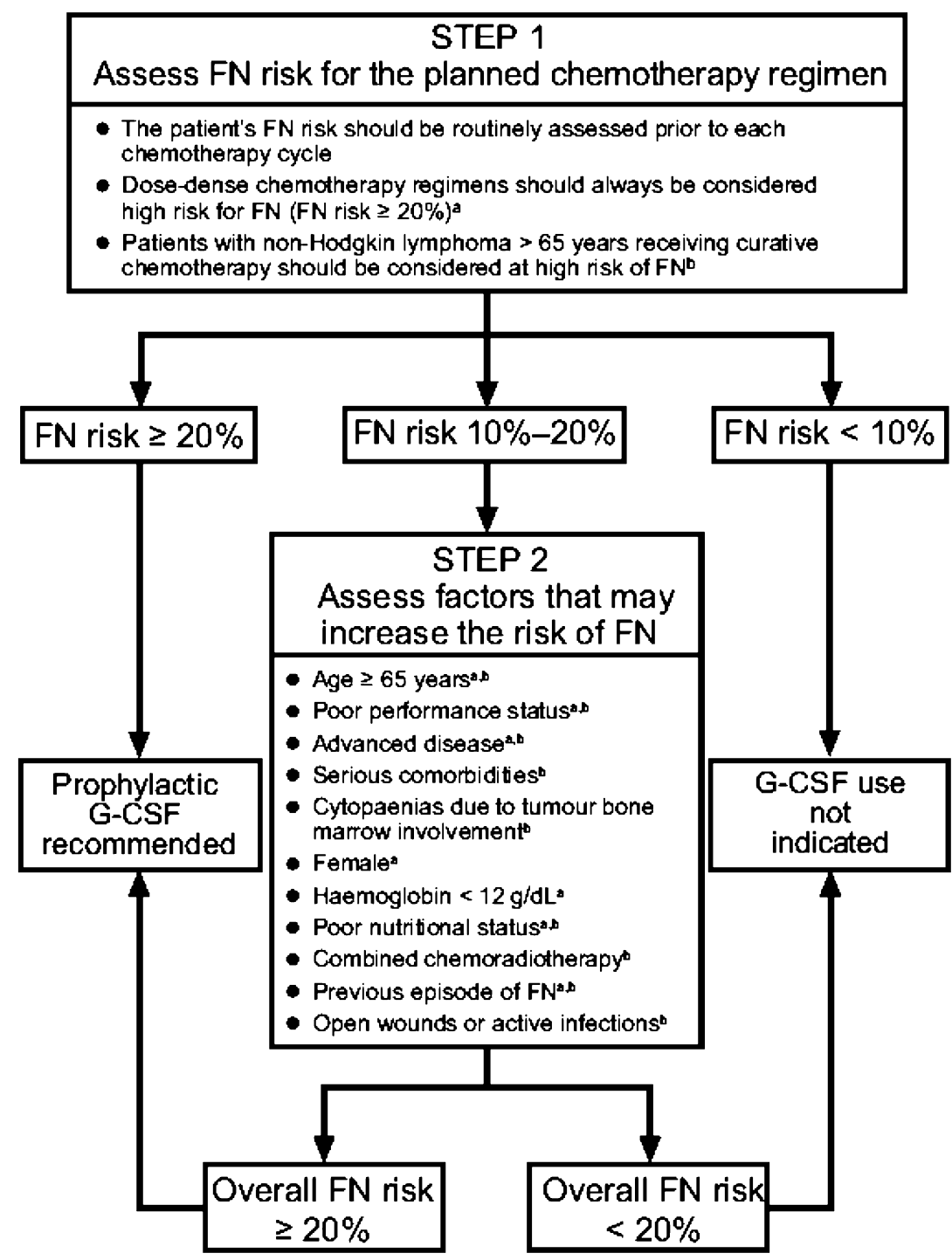

Figure 3 Patient assessment algorithm to determine whether prophylactic use of granulocyte colony-stimulating factor (G-CSF) is appropriate, based on the 2006 guidelines for G-CSF of the European Organisation for Research and Treatment of Cancer and of the American Society of Clinical Oncology. FN indicates febrile neutropenia and NHL indicated non-Hodgkin lymphoma: ${ }^{a}$ Aapro et al., 2006 and ${ }^{\text {bS }}$ ith et al., 2006.

more-experienced clinicians stay up-to-date with the latest evidence.

The successful implementation of guidelines requires that stakeholders be identified and engaged early in the process. To this end, guidelines should be created by a multidisciplinary team that includes, at a minimum, one or more nurses, a physician and, depending on the size of the clinic, a physician assistant, pharmacist, and administrator. When members of the team have an opportunity to provide input into the development of guidelines, they are more likely to support their integration at the practice (Maxwell and Stein, 2006).

A suggested process for adapting national guidelines into practice-specific guidelines is outlined in Figure 4 (Maxwell and Stein, 2006). The first step is to form the multidisciplinary team, which should become thoroughly familiar with the ASCO, EORTC, and NCCN guidelines. The team should then perform a chart review to obtain baseline data about rates of $\mathrm{CIN}$-related dose modification, $\mathrm{FN}$, and $\mathrm{FN}$ related hospitalisation, infection, and mortality in the clinic's own patients. These data will be helpful in addressing any questions that clinic decision-makers may have about the need for closer attention to G-CSF prophylaxis. Next, the team should create tools and procedures, such as a list of high-risk chemotherapy regimens, a risk assessment checklist, and/or an algorithm adapted from Figure 3. The team should discuss the practice-specific documents and procedures with the physicians and other decision-makers, with reference to the baseline data collected in the chart review. It may be useful to propose a "pilot study" in which the guidelines will be used for a limited time with a small number of patients and then be reevaluated.

Once the documents and procedures have been approved, the team should train all clinic personnel who will be using them. The emphasis of nurse training should be the nurse's 


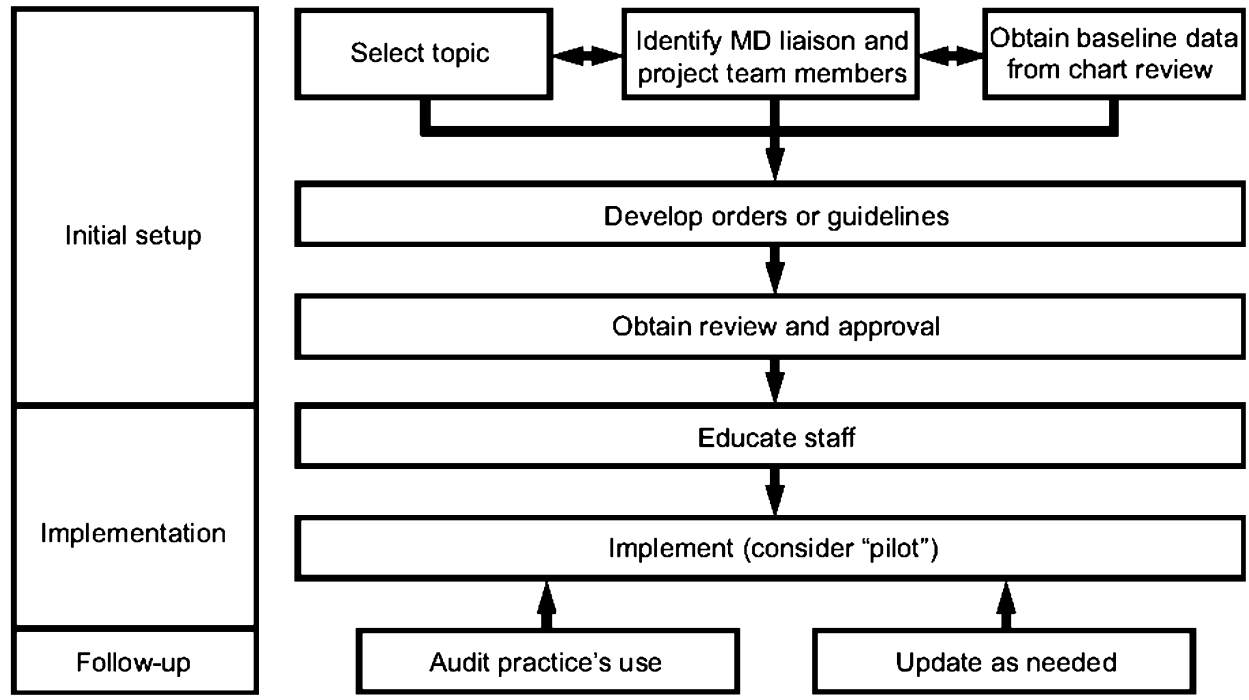

Figure 4 Process for integrating evidence-based guidelines into nursing practice (Maxwell and Stein, 2006). Published in Community Oncology, volume 3, Maxwell, Stein, Implementing evidence-based guidelines for preventing chemotherapy-induced neutropenia: from paper to clinical practice, 530-536, Copyright Elsevier 2006.

role in managing $\mathrm{CIN}$ and $\mathrm{FN}$, as discussed above. The team should conduct an ongoing audit of the staff's use of the guidelines, by chart review, to correct any misinterpretations and uncover barriers to implementation. For example, complaints about lack of time can be addressed by showing how the new tools and procedures increase efficiency. Audits can also be useful in documenting improvements in patient outcomes.

\section{Impact of $\mathrm{FN}$ risk assessment on patient outcomes}

There is evidence from nurse-driven research that the implementation of CSF practice guidelines improves patient outcomes (Donohue, 2006; Doyle, 2006; Maxwell et al., 2002; Michelson et al., 2002; White and Keehne-Miron, 2002; White et al., 2005). Although protocols and assessment tools have differed from centre to centre, a number of teams have observed significant improvements in patient outcomes after nurses became involved in evaluating FN risk.

Donohue (2006) reports on a retrospective chart review of 85 adult patients treated with new courses of chemotherapy, of whom 35 had been evaluated for FN risk in 2003 by a nurse, nurse practitioner, or physician. The risk factors considered were chemotherapy regimen with $\geqslant 40 \%$ risk of FN (the standard in 2003 according to ASCO guidelines), age $\geqslant 70$ years with combination chemotherapy, bone marrow involvement or compromise, open wounds, history of FN, first-cycle ANC $\leqslant 500 / \mathrm{mm}^{3}$, or serum albumin level $\leqslant 3.5 \mathrm{~g} /$ $\mathrm{dL}$. Patients assessed for FN risk were less likely to develop $\mathrm{FN}$, be hospitalised for $\mathrm{FN}$, be treated with intravenous antibiotics, or require chemotherapy dose reductions or dose delays. The difference was statistically significant for dose delays (required for $9 \%$ of patients evaluated for FN risk compared with $32 \%$ of the comparison group, $p=0.01$ ).

In a similar study, Doyle (2006) used a more detailed assessment checklist to prospectively evaluate FN risk in 189 patients undergoing chemotherapy from October 2004 through September 2005. That group was compared with 155 patients who had been treated from October 2003 through September 2004, without being evaluated for FN risk. Implementation of the assessment tool significantly reduced the number of hospitalisations for $\mathrm{FN}$, from $9.7 \%$ in the comparison group to $2.1 \%$ in the group evaluated for $\mathrm{FN}$ risk $(p=0.003)$. The total number of hospital days also decreased, from 117 to 24 , as did the average length of hospital stay, from 7.8 days to 6 days.

Table 4 summarises the results of these studies and data reported by three other groups of nurses who assessed patient outcomes after implementing guidelines for CSF prophylaxis. These studies all show that simple changes in practice can improve outcomes.

\section{Summary}

Despite the benefits of preventing $\mathrm{FN}$ and its consequences, G-CSF may not be considered for all patients receiving myelosuppressive chemotherapy, for a variety of reasons. The guidelines recently published by ASCO, EORTC, and NCCN provide evidence for directing G-CSF treatment, as well as increased nursing surveillance and additional education, toward patients who are at greatest risk of FN and are most likely to benefit. There is striking similarity between the three sets of guidelines, particularly with regard to the recommendation that adults need primary prophylaxis with CSFs when the overall risk of $\mathrm{FN}$ is $\geqslant 20 \%$.

It is now well established that G-CSF prophylaxis reduces the incidence of $\mathrm{FN}$ and $\mathrm{FN}$-related hospitalisation, and high-level evidence indicates that G-CSF reduces infectionrelated mortality and the need for chemotherapy dose modification. Oncology nurses can help improve patient outcomes by becoming actively involved in identifying patients who are candidates for prophylactic G-CSF. The guidelines can be useful in helping oncology nurses initiate 
Table 4 Patient outcomes after implementation of CSF guidelines by nurses.

\begin{tabular}{|c|c|c|c|}
\hline Authors & Type of practice & Type of intervention & Outcomes \\
\hline Donohue (2006) & Small community oncology clinic & FN risk assessment tool & $\begin{array}{l}\downarrow \text { FN } \\
\downarrow \text { Dose reductions } \\
\downarrow \text { Dose delays } \\
\downarrow \text { IV antibiotic use } \\
\downarrow \text { FN-related hospitalisations }\end{array}$ \\
\hline Doyle (2006) & Veterans oncology clinic & FN risk assessment tool & $\begin{array}{l}\downarrow \text { FN-related hospitalisations } \\
\downarrow \text { Length of hospital stays }\end{array}$ \\
\hline Maxwell et al. (2002) & Large community oncology clinic & CIN management protocol & $\begin{array}{l}\downarrow \text { Dose reductions } \\
\downarrow \text { Dose delays } \\
\downarrow \text { FN-related hospitalisations } \\
\uparrow R D I\end{array}$ \\
\hline Michelson et al. (2002) & Hospital outpatient clinic & CIN management protocol & $\begin{array}{l}\downarrow \text { Dose reductions } \\
\uparrow R D I\end{array}$ \\
\hline White and Keehne-Miron (2002) & Large community oncology clinic & CIN management protocol & $\begin{array}{l}\downarrow F N \\
\downarrow \text { Dose delays } \\
\uparrow R D I\end{array}$ \\
\hline
\end{tabular}

Abbreviations: CIN, chemotherapy-induced neutropenia; CSF, colony-stimulating factor; FN, febrile neutropenia; RDI, relative dose intensity.

discussions within their practices about the value of multidisciplinary approaches to preventing FN.

\section{Conflict of interest statement}

Nora Kearney has received honoraria from and served as a consultant to Amgen (Europe) $\mathrm{GmbH}$. Christopher Friese has received honoraria from and served as a consultant to Amgen, Inc.

\section{Acknowledgements}

The authors thank Faith Reidenbach and Supriya Srinivasan for writing and editorial support. Amgen (Europe) $\mathrm{GmbH}$ sponsored an external agency for writing support.

\section{References}

Aapro, M.S., Cameron, D.A., Pettengell, R., Bohlius, J., Crawford, J., Ellis, M., et al., 2006. EORTC guidelines for the use of granulocyte-colony stimulating factor to reduce the incidence of chemotherapy-induced febrile neutropenia in adult patients with lymphomas and solid tumours. European Journal of Cancer 42, 2433-2453.

American Society of Clinical Oncology. American Society of Clinical Oncology Guidelines Procedures Manual. Available online at: 〈http://www.asco.org/ac/1,1003,12-002562-00_ 18-0026185-00_19-00-00_20-001,00.asp >. Accessed December 20, 2005.

Ardizzoni, A., Favaretto, A., Boni, L., Baldini, E., Castiglioni, F., Antonelli, P., et al., 2005. Platinum-etoposide chemotherapy in elderly patients with small-cell lung cancer: results of a randomized multicenter phase II study assessing attenuateddose or full-dose with lenograstim prophylaxis-a Forza Oper- ativa Nazionale Italiana Carcinoma Polmonare and Gruppo Studio Tumori Polmonari Veneto (FONICAP_GSTPV) study. Journal of Clinical Oncology 23, 569-575.

Bodey, G.P., Buckley, M., Sathe, Y.S., Freireich, E.J., 1966. Quantitative relationships between circulating leukocytes and infection in patients with acute leukemia. Annals of Internal Medicine 64, 328-340.

Bonadonna, G., Moliterni, A., Zambetti, M., Daidone, M.G., Pilotti, S., Gianni, L., Valagussa, P., 2005. 30 years' follow up of randomised studies of adjuvant CMF in operable breast cancer: cohort study. British Medical Journal 330, 217.

Bonneterre, J., Roche, H., Kerbrat, P., Bremond, A., Fumoleau, P., Namer, M., et al., 2005. Epirubicin increases long-term survival in adjuvant chemotherapy of patients with poor-prognosis, node-positive, early breast cancer: 10-year follow-up results of the French Adjuvant Study Group 05 randomized trial. Journal of Clinical Oncology 23, 2686-2693.

Budman, D.R., Berry, D.A., Cirrincione, C.T., et al., 1998. Dose and dose intensity as determinants of outcome in the adjuvant treatment of breast cancer. Journal of the National Cancer Institute 90, 1205-1211.

Caggiano, V., Weiss, R.V., Rickert, T.S., Linde-Zwirble, W.T., 2005. Incidence, cost, and mortality of neutropenia hospitalization associated with chemotherapy. Cancer 103, 1916-1924.

Cordonnier, C., Herbrecht, R., Buzyn, A., et al., 2005. Risk factors for Gram-negative bacterial infections in febrile neutropenia. Haematologica 90, 1102-1109.

Cosler, L.E., Calhoun, E.A., Agboola, O., Lyman, G.H., 2004. Effects of indirect and additional direct costs on the risk threshold for prophylaxis with colony-stimulating factors in patients at risk for severe neutropenia from cancer chemotherapy. Pharmacotherapy 24, 488-494.

Crawford, J., Ozer, H., Stoller, R., Johnson, D., Lyman, G., Tabbara, I., et al., 1991. Reduction by granulocyte colony-stimulating factor of fever and neutropenia induced by chemotherapy in patients with small-cell lung cancer. New England Journal of Medicine 325, 164-170. 
Crawford, J., Dale, D.C., Lyman, G.H., 2004a. Chemotherapyinduced neutropenia: risks, consequences, and new directions for its management. Cancer 100, 228-237.

Crawford, J., Wolff, D., Culakova, E., Poniewierski, M.S., Selby, C. Dale, D.C., Lyman, G.H., for the ANC Study Group, 2004b. Firstcycle risk of severe and febrile neutropenia in cancer patients receiving systemic chemotherapy: results from a prospective nationwide study. Poster presented at Annual Meeting of the American Society of Hematology, December 4-7, 2004, San Diego, CA, USA (Abstract 2210).

Crawford, J., Althaus, B., Armitage, J., Balducci, L., Blayney, D.W., Cataland, S.R., et al., 2006. Myeloid Growth Factors in Cancer Treatment: The National Comprehensive Cancer Network Clinical Practice Guidelines in Oncology, Version 1.2006. Available online at: 〈http://www.nccn.org 〉. Accessed October 12, 2006.

Dale, D.C., McCarter, G.C., Crawford, J., Lyman, G.H., 2003. Myelotoxicity and dose intensity of chemotherapy: reporting practices from randomized clinical trials. Journal of the National Comprehensive Cancer Network 1, 440-454.

De Bock, R., Cometta, A., Kern, W., Aoun, M., Caballero, D., Engelhard, D., Schaffner, A., Galazzo, M., Paesmans, M., vanDenbergh, M., Viscoli, C., for the International Antimicrobial Therapy Group of the EORTC, et al., 2001. Incidence of single agent gram-negative bacteremias in neutropenic cancer patients in EORTC-IATG trials of empirical therapy for febrile neutropenia. Presented at 41st Interscience Conference on Antimicrobial Agents and Chemotherapy, December 16-19, 2001, Chicago, IL, USA (Abstract L-773).

Donohue, R., 2006. Development and implementation of a risk assessment tool for chemotherapy-induced neutropenia. Oncology Nursing Forum 33, 347-352.

Doyle, A., 2006. Prechemotherapy assessment of neutropenic risk. Oncology, Nurse Edition 20 (10 Suppl. 7) Available online at: 〈http://cancernetwork.com/nurses-edition $\rangle$. Accessed November 24, 2006.

Early Breast Cancer Trialists' Collaborative Group, 2005. Effects of chemotherapy and hormonal therapy for early breast cancer on recurrence and 15-year survival: an overview of the randomised trials. Lancet 365, 1687-1717.

Epelbaum, R., Faraggi, D., Ben-Arie, Y., Ben-Shahar, M., Haim, N., Ron, Y., et al., 1990. Survival of diffuse large cell lymphoma: a multivariate analysis including dose intensity variables. Cancer 66, 1124-1129.

Green, M.D., Koelbl, H., Baselga, J., Galid, A., Guillem, V., Gascon, P., et al., 2003. A randomized double-blind multicenter phase III study of fixed-dose single-administration pegfilgrastim versus daily filgrastim in patients receiving myelosuppressive chemotherapy. Annals of Oncology 14, 29-35.

Gáytan-Martinez, J., Mateos-Garcia, E., Sánchez-Cortes, E., Gonzalez-Llaven, J., Casanova-Cardiel, L.J., Fuentes-Allen, J.L., 2000. Microbiological findings in febrile neutropenia. Archives of Medical Research 31, 388-392.

Hackshaw, A., Sweetenham, J., Knight, A., 2004. Are prophylactic haematopoietic growth factors of value in the management of patients with aggressive non-Hodgkin's lymphoma? British Journal of Cancer 90, 1302-1305.

Holmes, F.A., O’Shaughnessy, J.A., Vukelja, S., Jones, S.E., Shogan, J., Savin, M., et al., 2002. Blinded, randomized, multicenter study to evaluate single administration pegfilgrastim once per cycle versus daily filgrastim as an adjunct to chemotherapy in patients with high-risk stage II or stage III/IV breast cancer. Journal of Clinical Oncology 20, 727-731.

Kuderer, N.M., Crawford, J., Dale, D.C., Lyman, G.H., 2005. Metaanalysis of prophylactic granulocyte colony-stimulating factor in cancer patients receiving chemotherapy. Journal of Clinical Oncology 23 (16S), 758s (Abstract 8117).
Kuderer, N.M., Dale, D.C., Crawford, J., Cosler, L.E., Lyman, G.H., 2006. Mortality, morbidity, and cost associated with febrile neutropenia in adult cancer patients. Cancer 106, 2258-2266.

Kwak, L.W., Halpern, J., Olshen, R.A., Horning, S.J., 1990. Prognostic significance of actual dose intensity in diffuse largecell lymphoma: results of a tree-structured survival analysis. Journal of Clinical Oncology 8, 963-977.

Leese, B., 1993. The costs of treating febrile neutropenia in six UK hospitals. European Journal of Cancer 29A (Suppl. 7), S15-S18.

Lenhart, C., 2005. Relative dose intensity: improving cancer treatment and outcomes. Oncology Nursing Forum 32, 757-764.

Link, B.K., Budd, G.T., Scott, S., Dickman, E., Paul, D., Lawless, G., et al., 2001. Delivering adjuvant chemotherapy to women with early-stage breast carcinoma: current patterns of care. Cancer 92, 1354-1367.

Lyman, G.H., 2005. Guidelines of the National Comprehensive Cancer Network on the use of myeloid growth factors with cancer chemotherapy: a review of the evidence. Journal of the National Comprehensive Cancer Network 3, 557-571.

Lyman, G.H., Kuderer, N.M., 2003. Epidemiology of febrile neutropenia. Supportive Cancer Therapy 1, 23-25.

Lyman, G.H., Kuderer, N.M., Djulbegovic, B., 2002. Prophylactic granulocyte colony-stimulating factor in patients receiving doseintensive cancer chemotherapy: a meta-analysis. The American Journal of Medicine 112, 406-411.

Lyman, G.H., Dale, D.C., Crawford, J., 2003. Incidence and predictors of low dose-intensity in adjuvant breast cancer chemotherapy: a nationwide study of community practices. Journal of Clinical Oncology 21, 4524-4531.

Lyman, G.H., Dale, D.C., Friedberg, J., Crawford, J., Fisher, R.I., 2004. Incidence and predictors of low chemotherapy doseintensity in aggressive non-Hodgkin's lymphoma: a nationwide study. Journal of Clinical Oncology 22, 4302-4311.

Lyman, G.H., Kuderer, N.M., Crawford, J., Wolff, D.A., Culakova, E., Poniewierski, M.S., et al., 2006. Prospective validation of a risk model for first cycle neutropenic complications in patients receiving cancer chemotherapy. Journal of Clinical Oncology 24 (Abstract 8561).

López, A., Alonso, J.D., Gómez-Codina, J., Novo, A., Herrera, C., Lara, N., on behalf of the ENIA Study Group, et al., 2006. Febrile neutropenia in lymphoma patients is associated with substantial resource use and healthcare costs in clinical practice in Spain. Blood 108 (Abstract 5512).

Maxwell, C., Stein, A., 2006. Implementing evidence-based guidelines for preventing chemotherapy-induced neutropenia: from paper to clinical practice. Community Oncology 3, 530-536.

Maxwell, C., Winkler, L., Lottenberg, M., 2002. Nurse-driven neutropenia management guidelines: improving patient outcomes through evidence-based practice. Presented at 27th Annual Congress of Oncology Nursing Society, April 18-21, 2002, Washington, DC, USA (Abstract 171).

Mayordomo, J.I., Castellanos, J., Pernas, S., Ruiz-Borrego, M., Velasco, A., Frau, A., on behalf of the ENIA Study Group, et al., 2006. Cost analysis of febrile neutropenia management of breast cancer patients in clinical practice in Spain. Annals of Oncology 17 (Suppl. 9) (Abstract 617P).

Michelson, J.L., Shedlock, K., Bergen, S., Doherty, E., Emens, C., Parrone, M.K., 2002. Using evidence to implement a collaborative neutropenia management protocol for improving chemotherapy delivery. Presented at 27th Annual Congress of Oncology Nursing Society, April 18-21, 2002, Washington, DC, USA (Abstract 169).

Oncology Nursing Society, 2006. Evidence Based Practice Resource Area. Available online at: 〈http://onsopcontent.ons.org/toolkits/ evidence/index.shtml $\rangle$. Accessed October 13, 2006.

Pettengell, R., Bosly, A., Szucs, T.D., Jackisch, C., Leonard, R., Paridaens, R., et al. on behalf of the Impact of Neutropenia on Chemotherapy Study Group (INC-EU), 2006. Impact of febrile 
neutropenia and colony stimulating factor use on chemotherapy delivery in patients with lymphoma: results from the INC-EU prospective observational European neutropenia study. Poster presented at Annual Meeting of the American Society of Hematology, December 9-12, 2006, Orlando, FL, USA (Abstract 550723).

Picozzi, V.J., Pohlman, B.L., Morrison, V.A., Lawless, G.D., Lee, M.W., Kerr, R.O., et al., 2001. Patterns of chemotherapy administration in patients with intermediate-grade non-Hodgkin's lymphoma. Oncology (Huntington, New York) 15, 1296-1306.

Repetto, L., Biganzoli, L., Koehne, C.H., Luebbe, A.S., Soubeyran, P., Tjan-Heijnen, V.C., Aapro, M.S., 2003. EORTC Cancer in the Elderly Task Force guidelines for the use of colony-stimulating factors in elderly patients with cancer. European Journal of Cancer 39, 2264-2272.

Sackett, D.L., Rosenberg, W.M., Gray, J.A., Haynes, R.B., Richardson, W.S., 1996. Evidence based medicine: what it is and what it isn't. British Journal of Cancer 312, 71-72.

Smith, T.J., Khatcheressian, J., Lyman, G.H., Ozer, H., Armitage, J.O., Balducci, L., et al., 2006. 2006 update of recommendations for the use of white blood cell growth factors: an evidence-based clinical practice guideline. Journal of Clinical Oncology 24, 3187-3205.

Timmer-Bonte, J.N., de Boo, T.M., Smit, H.J., Biesma, B., Wilschut, F.A., Cheragwandi, S.A., et al., 2005. Prevention of chemother- apy-induced febrile neutropenia by prophylactic antibiotics plus or minus granulocyte colony-stimulating factor in small-cell lung cancer: a Dutch randomized phase III study. Journal of Clinical Oncology 23, 7974-7984.

Trillet-Lenoir, V., Green, J., Manegold, C., Von Pawel, J., Gatzemeier, U., Lebeau, B., et al., 1993. Recombinant granulocyte colony stimulating factor reduces the infectious complications of cytotoxic chemotherapy. European Journal of Cancer 29A, 319-324.

Vogel, C.L., Wojtukiewicz, M.Z., Carroll, R.R., Tjulandin, S.A., Barajas-Figueroa, L.J., Wiens, B.L., et al., 2005. First and subsequent cycle use of pegfilgrastim prevents febrile neutropenia in patients with breast cancer: a multicenter, doubleblind, placebo-controlled phase III study. Journal of Clinical Oncology 23, 1178-1184.

White, N., Keehne-Miron, J., 2002. Assessing clinical outcomes in breast cancer patients in a community-based cancer center. Presented at 27th Annual Congress of Oncology Nursing Society, April 18-21, 2002, Washington, DC, USA (Abstract 102).

White, N., Maxwell, C., Michelson, J., Bedell, C., 2005. Protocols for managing chemotherapy-induced neutropenia in clinical oncology practices. Cancer Nursing 28, 62-69.

Zitella, L.J., Friese, C.R., Hauser, J., Gobel, B.H., Woolery, M., O'Leary, C., Andrews, F.A., 2006. Putting evidence into practice: prevention of infection. Clinical Journal of Oncology Nursing 10, 739-750. 